Manuscript prepared for Earth Syst. Dynam. Discuss.

with version 3.5 of the LATEX class copernicus_discussions.cls.

Date: 25 May 2012

\title{
The influence of vegetation on the ITCZ and South Asian Monsoon in HadCM3
}

M. P. McCarthy ${ }^{1}$, J. Sanjay ${ }^{2}$, B. B. B. Booth ${ }^{1}$, K. Krishnakumar ${ }^{2}$, and R. A. Betts ${ }^{1}$

${ }^{1}$ Met Office, Hadley Centre, Fitzroy Road, Exeter, EX1 2NY, UK

${ }^{2}$ Indian Institute of Tropical Meteorology,Pashan, Pune 411008, India

Correspondence to: M. P. McCarthy (mark.mccarthy@metoffice.gov.uk)

Supplementary Material 



Fig. 1. Difference in vegetation cover (as a fraction of each model grid cell) compared to WHS of (left) IGBP and (middle) TRIF and between (right) TRIFfut and TRIF. The upper row represents the difference in Broadleaf tree (BL), middle panel to shrub, and lower panel grass. 

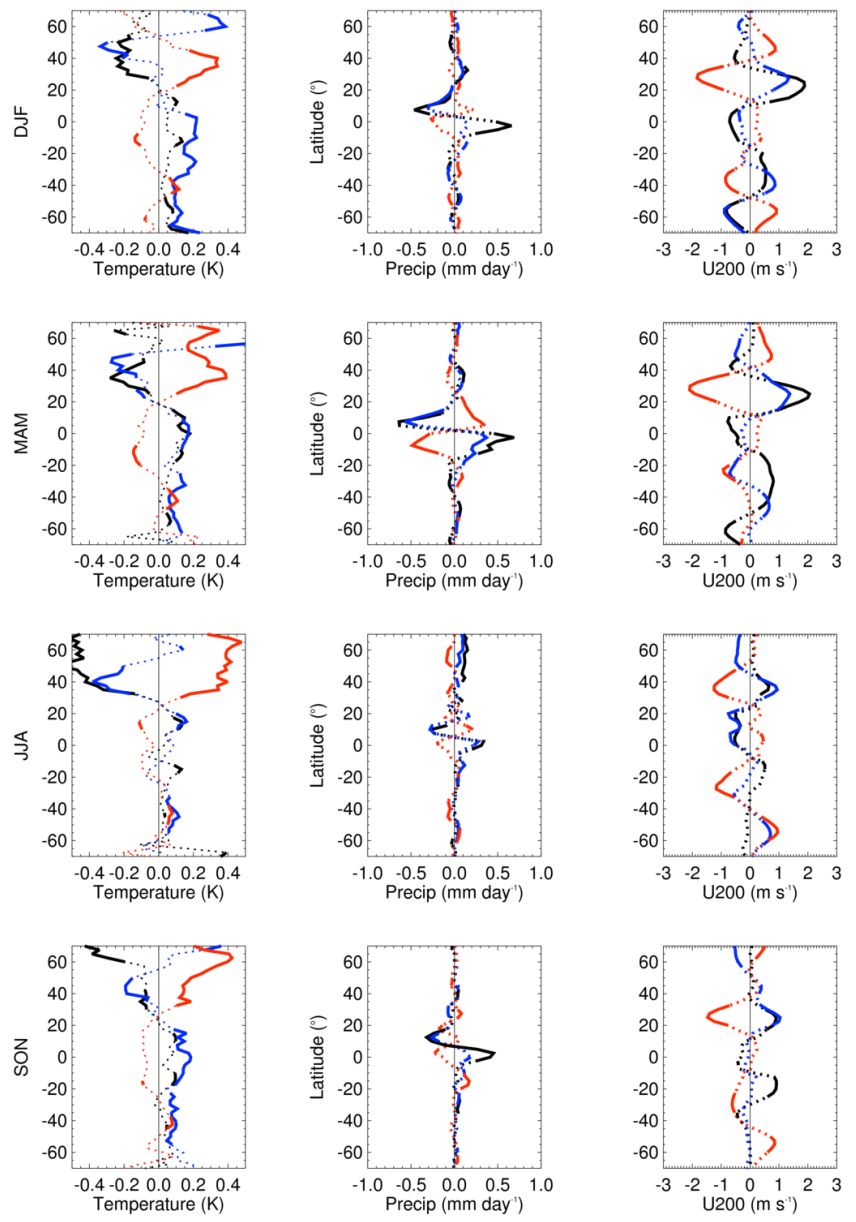

Fig. 2. Climate impact of imposed vegetation on (left) near surface air temperature, (middle) precipitation, and (right) $200 \mathrm{hPa}$ zonal wind. The zonal mgan differences between (black) IGBP-WHS, (blue) TRIF-WHS, and (red) TRIFfut-TRIF are shown for (top to bottom) DJF, MAM, JJA, and SON. Unbroken seoments renresent reoions where the difference is statistically sionificant at the $5 \%$ level hased on 

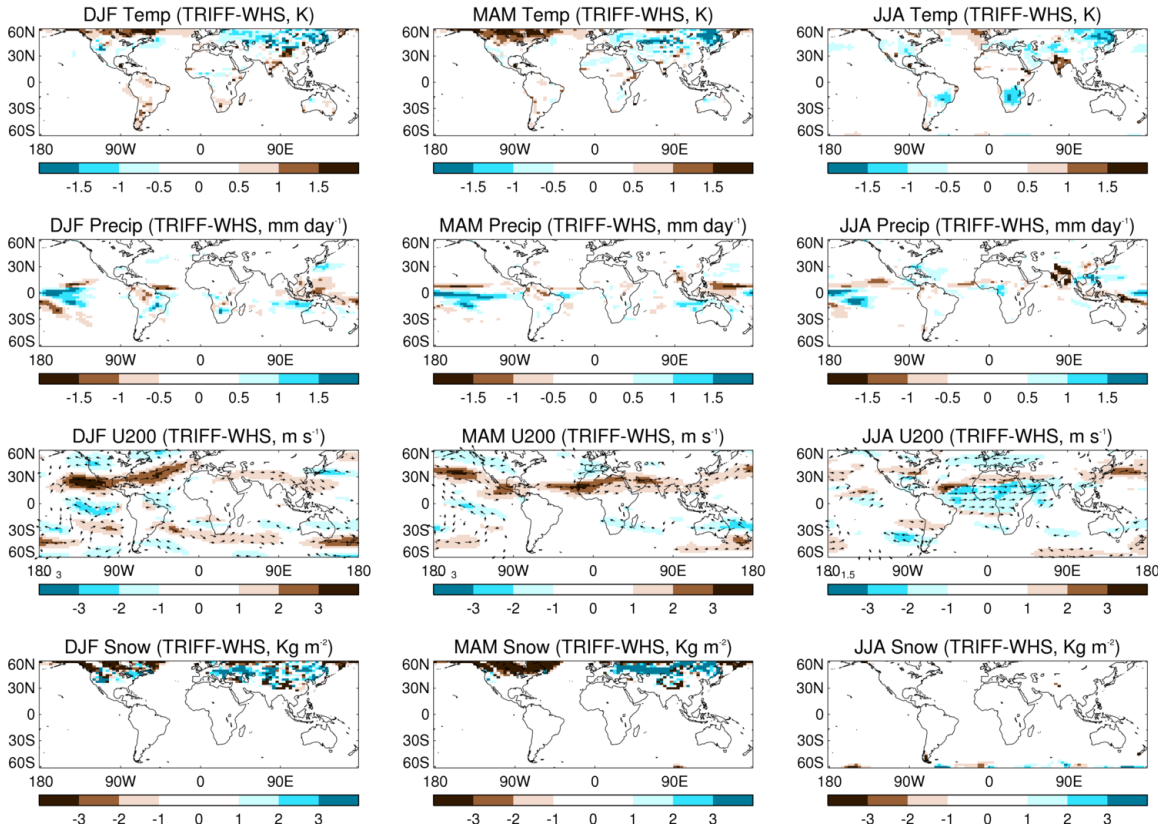

Fig. 3. Regional differences between TRIF and WHS for annual means of (top to bottom) temperature, precipitation, $200 \mathrm{hPa}$ zonal wind, and snow cover, for seasons (left) DJF, (middle) MAM, and (right) JJA. The wind vector anomalies are also included in the U200 plots. 